\title{
Effect of BMI on quality of life and depression levels after bariatric surgery
}

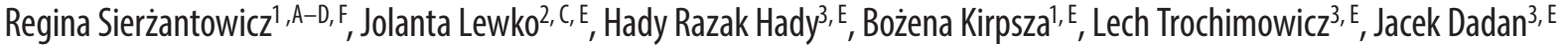 \\ ${ }^{1}$ Department of Surgical Nursing, Medical University of Bialystok, Poland \\ ${ }^{2}$ Department of Integrated Medical Care, Medical University of Bialystok, Poland \\ ${ }^{3}$ Department of General and Endocrine Surgery, Medical University of Bialystok, Poland \\ A - research concept and design; $\mathrm{B}$ - collection and/or assembly of data; $\mathrm{C}$ - data analysis and interpretation; \\ $D$ - writing the article; $E$ - critical revision of the article; $F$ - final approval of article
}

Address for correspondence

Regina Sierżantowicz

E-mail: renatasierz@wp.pl

Funding sources

None declared

\section{Conflict of interest}

None declared

Received on November 13, 2015

Revised on November 25, 2015

Accepted on March 17, 2016

\section{Abstract}

Background. Studies conducted in Poland have found that 1\% $(\sim 300,000)$ of Polish adults are obese. The degree of weight loss and reduction of discomfort associated with severe obesity are used to evaluate bariatric surgery outcomes. From the patient's point of view, QoL and mental health are the most important determinants of successful surgery, which is why interest in QoL assessment has increased.

Objectives. To assess the effect of BMI on quality of life and depression levels depending on the type of bariatric surgery.

Material and methods. The group included 57 women and 43 men aged 20-60 years (mean age 40 years) with BMl from 36 to 40 (31\%) and > 40 (69\%). Twelve patients (12\%) underwent laparoscopic adjustable gastric binding (LAGB), 58 (58\%) sleeve gastrectomy, and 30 (30\%) Roux-en-Y Gastric Bypass (RYGB). The Bariatric Analysis and Reporting Outcome System (BAROS) was used to assess QoL. The severity of mood disorders was assessed using the Self-Rating Scale of Depression and Anxiety.

Results. Six months or 1 year after bariatric surgery, the number of patients with BMI $>40$ had decreased from 69 to 14\%. We found that the time since bariatric surgery contributed to a significant $(p<0.01)$ difference in BAROS outcomes. In the long-term perspective, we observed better quality of life.

Conclusions. MA-QoL II is a useful tool in assessing bariatric surgery, including quality of life. Long-term monitoring will be essential in determining psychological changes and the degree of weight loss.

Key words: quality of life, depression, anxiety, bariatric surgical procedures

DOI

10.17219/acem/62246

\section{Copyright}

Copyright by Author(s)

This is an article distributed under the terms of the

Creative Commons Attribution Non-Commercial License

(http://creativecommons.org/licenses/by-nc-nd/4.0/) 
In recent years, the number of people with obesity has significantly increased worldwide. ${ }^{1}$ Recent data from the World Health Organization (WHO) indicate that 1.6 billion people are overweight and 400 million are obese $\left(\mathrm{BMI}>40 \mathrm{~kg} / \mathrm{m}^{2}\right) .^{2}$ The results of a nationwide Polish study, conducted under the NATPOL, Household Food Consumption and Anthropometric Survey (HFCAS), and WOBASZ programs, have shown that $1 \%$ of Poles have obesity $\left(\mathrm{BMI}>40 \mathrm{~kg} / \mathrm{m}^{2}\right)$, which is approximately 300,000 people. In selected rural populations, this percentage increased to $2.8 \%$, and in urban areas to $3 \% .^{3-6}$

Obesity leads to serious medical complications, such as type 2 diabetes, cardiovascular and respiratory diseases (e.g. coronary artery disease, myocardial infarction, hypertension, Chronic Obstructive Pulmonary Disease, embolism), as well as certain hormone-dependent cancers or colon cancer, osteoarthritis and infertility in women, and impotence in men. ${ }^{6-8}$ The psychological consequences of obesity include low self-esteem, anxiety and depression. ${ }^{9}$

In addition to the physical consequences, obesity causes psychosocial disability and decreases quality of life (QoL). Patients have significant limitations in performing many daily tasks. Most have professional problems and difficulty finding a job due to appearance, the high cost of treatment, and frequent absenteeism. ${ }^{10}$ Social isolation and addiction are widespread and many patients die prematurely. ${ }^{9-12}$

Conservative treatment based on a low-calorie diet, lifestyle modifications, increased physical activity, and drug therapy is not always effective. Currently, the best long-term results are achieved through bariatric surgery. ${ }^{13-16}$ The degree of weight loss and reduction of discomfort associated with severe obesity are used to evaluate bariatric surgery outcomes. ${ }^{17}$ The main evaluation results of bariatric surgery have traditionally focused on the degree of weight loss and control of comorbidities. ${ }^{17,18}$ From the patient's perspective, an important element in assessing the effectiveness of surgery is an improvement in psychosocial functioning and quality of life. ${ }^{19}$

The aim of this study was to assess the effect of BMI on QoL and depression levels depending on the type of bariatric surgery.

\section{Material and methods}

The study was conducted at the Department of General and Endocrine Surgery, Medical University of Bialystok, Poland, on 100 patients after bariatric surgery. The research was conducted using the prospective-cohort method. A sample of patients was recruited with consecutive admission to the hospital.

The group included 57 (57\%) women and 43 (43\%) men aged 20-60 years (mean age 40 years) with BMI from 36 to $40(31 \%)$ and > 40 (69\%). Comorbidities included: hypertension (35\%), type 2 diabetes (28\%), cholelithiasis (22\%) and lower limb varicose veins $(8 \%)$. Nine patients underwent Helicobacter pylori eradication therapy before surgery. The reason for bariatric surgery in $72 \%$ of the patients was health problems. People with secondary (35\%) and higher education (32\%) more frequently decided to undergo surgery.

Twelve patients (12\%) underwent laparoscopic adjustable gastric banding (LAGB), 58 (58\%) sleeve gastrectomy, and 30 (30\%) Roux-en-Y Gastric Bypass (RYGB).

\section{Measurement}

The Bariatric Analysis and Reporting Outcome System (BAROS) was used to assess quality of life. BAROS was developed by psychologists Moorehead and ArdeltGattinger for patients with severe obesity. ${ }^{20,21}$ BAROS evaluates the percent of excess weight loss (\%EWL) and excess BMI loss (EBL) calculated using the formula: $\% \mathrm{EBMIL}=100$-[(current BMI-25/initial BMI-25) $\times 100]$, improvement and/or control of comorbidities, and 5 aspects of QoL (self-esteem, physical, social, professional and sexual activity, complications and reoperations). The final score is based on improvement, deterioration or no change in the 5 aforementioned aspects. Each aspect is rated as: much worse, worse, unchanged, improved or very improved, scored, respectively: $-0.5,-0.25,0,+0.25$ and +0.5 .

The severity of mood disorders (depression, anxiety) was assessed using the Self-Rating Scale of Depression and Anxiety developed by Kokoszka. ${ }^{22}$ It is possible to record the following on the 10-point scale: mood, energy, strength of interests, experiencing pleasure, speed of thought and action, anxiety, mental tension, nervousness, fear of a specific threat, fear of what might happen, feelings of physical stress, and avoiding anxiety-inducing situations. Internal consistency of the scale for anxiety and depression is 0.96 . Each statement can receive from 0 to 10 points; the maximum number of points in each subscale is 100. In interpreting the results, we assumed that $0-8$ points meant that the existence of depressive and/or anxiety disorders was low; 9-27 points meant an average possibility of a depressive and/or anxiety disorder. The higher the score from 28 to 100 points meant the greater the severity of the disorders. The results are translated into a sten score. The results from 0 to 8 points (sten score 1-4) should be interpreted as the existence of depressive and/or anxiety disorders is low, results from 9 to 27 points (sten score 5-6) as average, results from 28 to 100 points (sten score $7-10$ ) as high. ${ }^{22}$ We compared well-being before and after surgery.

An analysis of the medical records of the patients who underwent bariatric surgery consisted of obtaining information on the occurrence of postoperative complications and the severity/amelioration/regression of comorbidities. 
The study was conducted in the years 2013-2014. Patients were examined 6 months or 1 year after surgery during a check-up at the Outpatient Surgery Clinic.

The study was approved by the Bioethics Committee of the Medical University of Bialystok (number 12324579P).

\section{Inclusion criteria}

Patients included in the study met the guidelines developed by the National Institute for Health and Clinical Excellence (NICE) for bariatric surgery. These include: $\mathrm{BMI}>40$ or BMI $>35$ with at least 1 comorbity (e.g. cardiovascular diseases, sleep apnea, type 2 diabetes, musculoskeletal diseases caused by obesity impairing typical physical activity, etc.). ${ }^{3,15}$

\section{Exclusion criteria}

The study excluded patients with contraindications to anesthesia administration. ${ }^{3,15}$

\section{Surgical procedures}

Laparoscopic adjustable gastric banding (LAGB) was performed by placing a silicone band around the upper part of the stomach. The diameter of the band was controlled by a liquid feed through a port implanted under the skin above the left costal arch and connected by a drain with the band. The band divides the stomach into two parts: an upper pouch with a volume of about 25-40 mL, and a much bigger bottom section. Sleeve gastrectomy (SG) was done laparoscopically by total vertical stomach resection of the greater curvature.

The Roux-en-Y gastric bypass (RYGB) consisted of 3 steps: stomach reduction, gastroenterostomy, and then enteroenterostomy. All procedures were performed laparoscopically.
Table 1. BMI of patients before and after bariatric surgery

\begin{tabular}{|c|c|c|c|}
\hline BMI $\left(\mathrm{kg} / \mathrm{m}^{2}\right)$ & $\begin{array}{c}\text { Patients before } \\
\text { surgery } \\
\mathrm{n}(\%)\end{array}$ & $\begin{array}{c}\text { Patients after } \\
\text { surgery } \\
\mathrm{n}(\%)\end{array}$ & $\mathrm{p}$-value \\
\hline $25-30$ & - & $13(13)$ & \\
\hline $31-35$ & - & $38(38)$ & 0.001 \\
\hline $36-40$ & $31(31)$ & $35(35)$ & \\
\hline$>40$ & $69(69)$ & $14(14)$ & \\
\hline
\end{tabular}

\section{Statistical analysis}

Data analyses were conducted using the Statistical Package for Social Sciences (SPSS) v. 20.0. Questionnaire results are presented in the Table and Figures.

An analysis of the differences of the results of the brief Self-Rating Scale of Depression and Anxiety and BAROS was performed using the nonparametric test Wilcoxon Signed Ranks Test. A level of $\mathrm{p}<0.05$ was considered statistically significant.

\section{Results}

Six months or 1 year after bariatric surgery (LAGB, SG, RYGB), the number of patients with BMI > 40 had decreased from $69 \%$ to $14 \%$ ( $\mathrm{p}<0.001$ ). Weight loss decreased BMI to $25-30$ in $13 \%$ and $31-35$ in 38\% of the patients. Such BMI had not been observed before the treatment (Table 1).

Analyzing the occurrence of depression and anxiety by using the Self-Rating Scale of Depression and Anxiety after bariatric procedures, it was found that $16 \%$ of subjects had a low level of depression and anxiety. Almost half $(48 \%)$ of those surveyed had an average severity of depression and anxiety and a group of $36 \%$ of the respondents had high levels (Fig. 1).

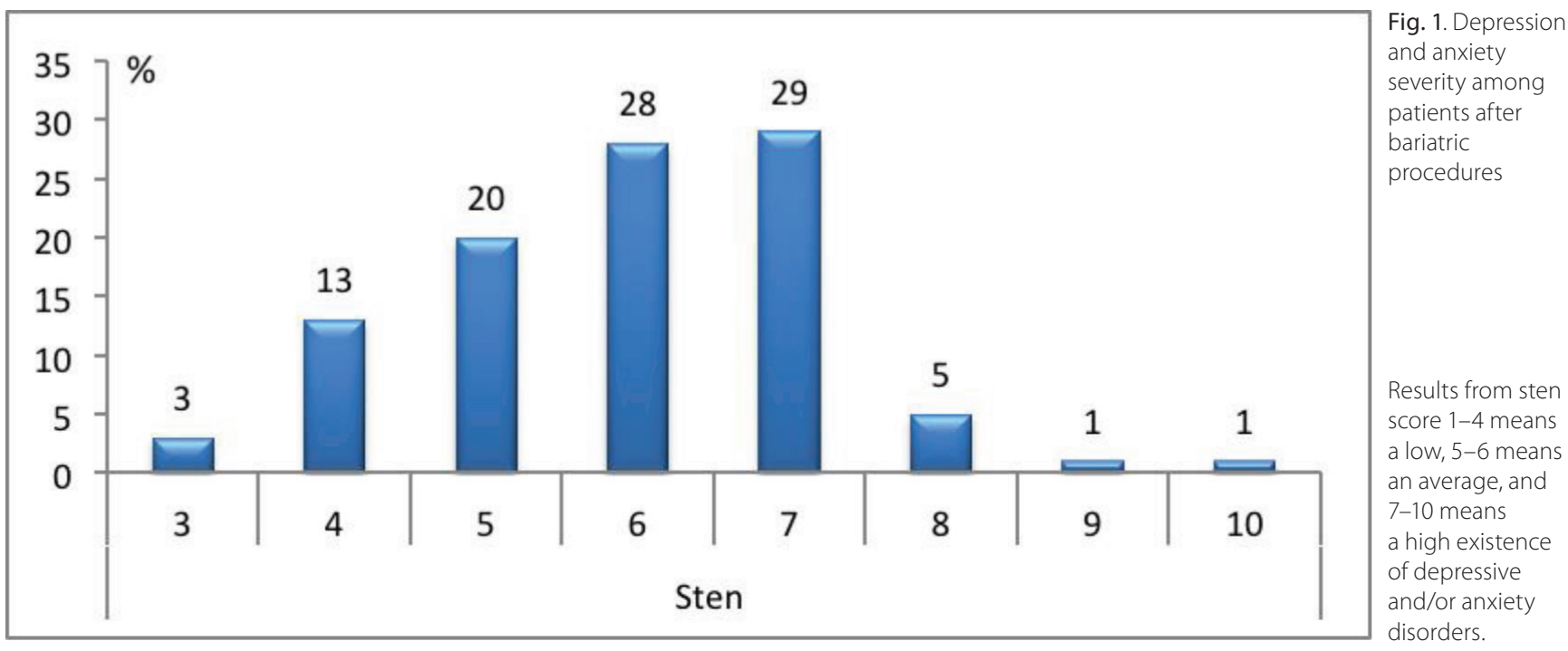


Final evaluation of QoL on BAROS showed 62\% of patients had good, very good or excellent bariatric surgery outcomes (Fig. 2). Eighteen percent of patients did not have positive outcomes.

The time since surgery had no significant effect on the results on the Self-Rating Scale of Depression and Anxiety in the group of treated patients. However, we found that the time since bariatric surgery contributed to a highly significant ( $<$ 0.01) difference in BAROS outcomes (Fig. 3). We found that the longer since surgery the higher the final BAROS score, from an average of 1.95 (median 2) for up to 6 months, through an average of 2.74 (median 3 ) in the period from half to 1 year, up to an average of 3.3 (median 3.5) for over 1 year.

In this study, there was no evidence that surgery type (LAGB, SG, RYGB), age, or sex had any effect on the re-

Fig. 2. BAROS evaluation of bariatric surgery outcomes

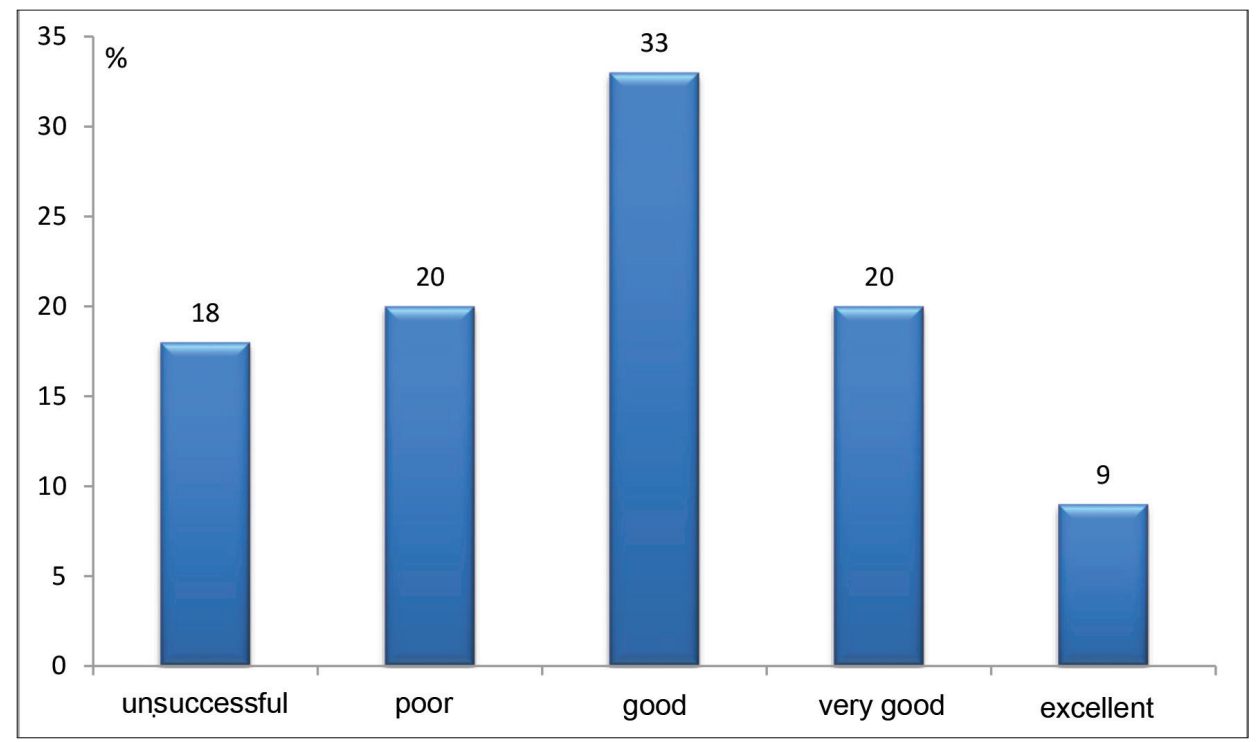

Fig. 3. Effect of time since bariatric surgery on QoL and depression and anxiety severity

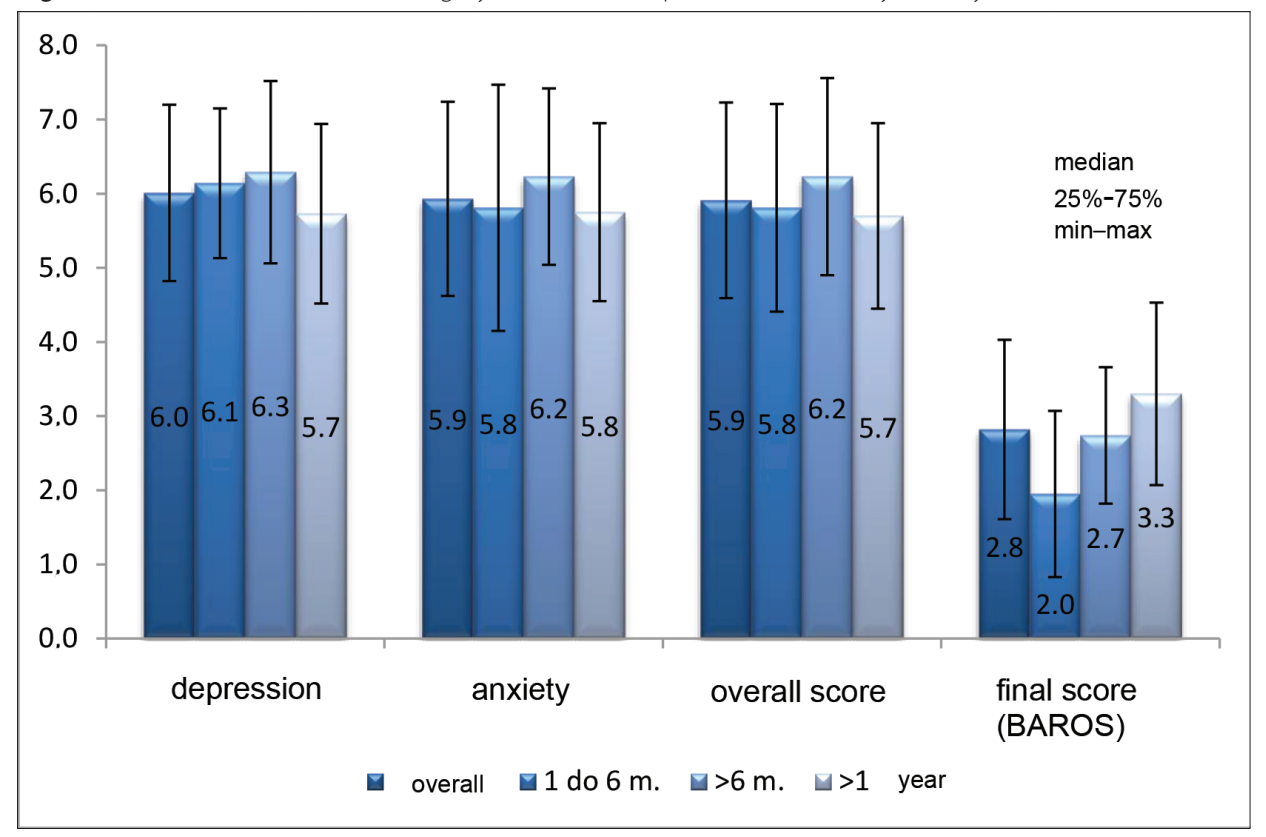

sults of the symptoms of depression and anxiety, and were independently associated with the QoL assessed on BAROS (Figs. 4-6).

\section{Discussion}

Bariatric surgery is now the last chance for good longterm outcomes when conservative and pharmacological therapy do not produce results.

BAROS, introduced by Oria and Moorehead in 1998, is an established and recognized tool for QoL evaluation in people with obesity. ${ }^{20,21}$ Bobowicz et al. used BAROS to assess sleeve gastrectomy (SG) outcomes in 84 patients 5 years after surgery. ${ }^{23}$ Positive changes were achieved in QoL in the physical, social and professional domains; and moderate improvement was noted in the sexual domain. An overall very good result was achieved in 30\% of patients, whereas no effects were reported by $13 \%$ of respondents. Better results are achieved by women, who had 46.5\% excess weight loss (EWL) compared with $35.3 \%$ for males.

Ribaric presented a 3-year follow-up HRQoL on BAROS of patients operated on in France using the Swedish adjustable gastric band (SAGB) method. ${ }^{24}$ The results were evaluated in the preoperative period and 1 , $3,6,12,18,24$ and 36 months after surgery. It was found that weight loss resulted in improved QoL over the 3 years of observation. The overall BAROS score increase from 1.4 preoperatively to $3.6(2.2$, $\mathrm{p}<0.001)$ after 3 years.

Zuger et al. evaluated RYGB and LAGB as treatment methods for obesity. ${ }^{25}$ After 5-year observations, they accepted 52\% EWL after LAGB and 79\% EWL after RYGB as effective criteria.

We found that the time since bariatric surgery, regardless of type, contributed to a highly significant $(\mathrm{p}<0.01)$ difference in BAROS outcomes. Also, the longer since surgery the higher the final BAROS assessment. 
More than half (62\%) of the patients assessed the surgery outcome as good, very good or excellent. Eighteen percent of patients did not have positive outcomes. Similar studies were conducted in the same center by Dadan et al., who evaluated patient QoL 6 months after LAGB and RYGB. ${ }^{26}$ They found that in both groups (LAGB and RYGB), QoL was evaluated as much better by $55 \%$ of the patients, better by $42 \%$, and unchanged by $3 \%$. Sierżantowicz et al. found a highly significant difference $(\mathrm{p}<0.0001)$ in BMI changes depending on surgery type. ${ }^{27} \mathrm{~A}$ higher reduction in BMI was achieved in RYGB surgery than LAGB and sleeve gastrectomy. Six months after surgery, body weight was reduced by an average of $30 \%$ EBL.

To assess the QoL of patients after bariatric in the physical dimension, it is necessary to analyze laboratory parameters, including ghrelin, insulin, glucose, triglycerides, HDL and LDL cholesterol. Abnormal values will help to determine the risk factors or types of comorbidities. Effective bariatric treatment reduces excess weight, improves the patient's general condition, and normalizes metabolic parameters, which significantly improves QoL. These assumptions have been confirmed by research conducted by Hady H.R. et al. ${ }^{28,29}$

Given the multidimensional nature of QoL, in addition to the clinical evaluation of patients after bariatric surgery, psychological assessment is equally important. Burgmer et al. conducted a study with the aim to assess QoL and identify psychological problems. ${ }^{30}$ Symptoms of anxiety and depression were analyzed using a questionnaire (Hospital Anxiety and Depression Scale - HADS) 1 and 2 years after bariatric surgery. The study showed significant differences between baseline assessment and the 2-year follow-up, where the severity of depressive symptoms in $40.5 \%$ of patients decreased to $16.4 \%$. No changes were observed in the evaluation of anxiety in the studied group.

Prior to surgery, $48 \%$ of the patients indicated average depression and anxiety levels measured on the Self-Rating Scale of Depression and Anxiety. Repeated evaluation 6 months or 1 year after bariatric surgery showed a downward trend of depression and anxiety symptoms. There were no statistically significant differences between surgery type, sex or age.
Fig. 4. Effect of depression, anxiety and QoL quality of life according to of the type of bariatric procedure
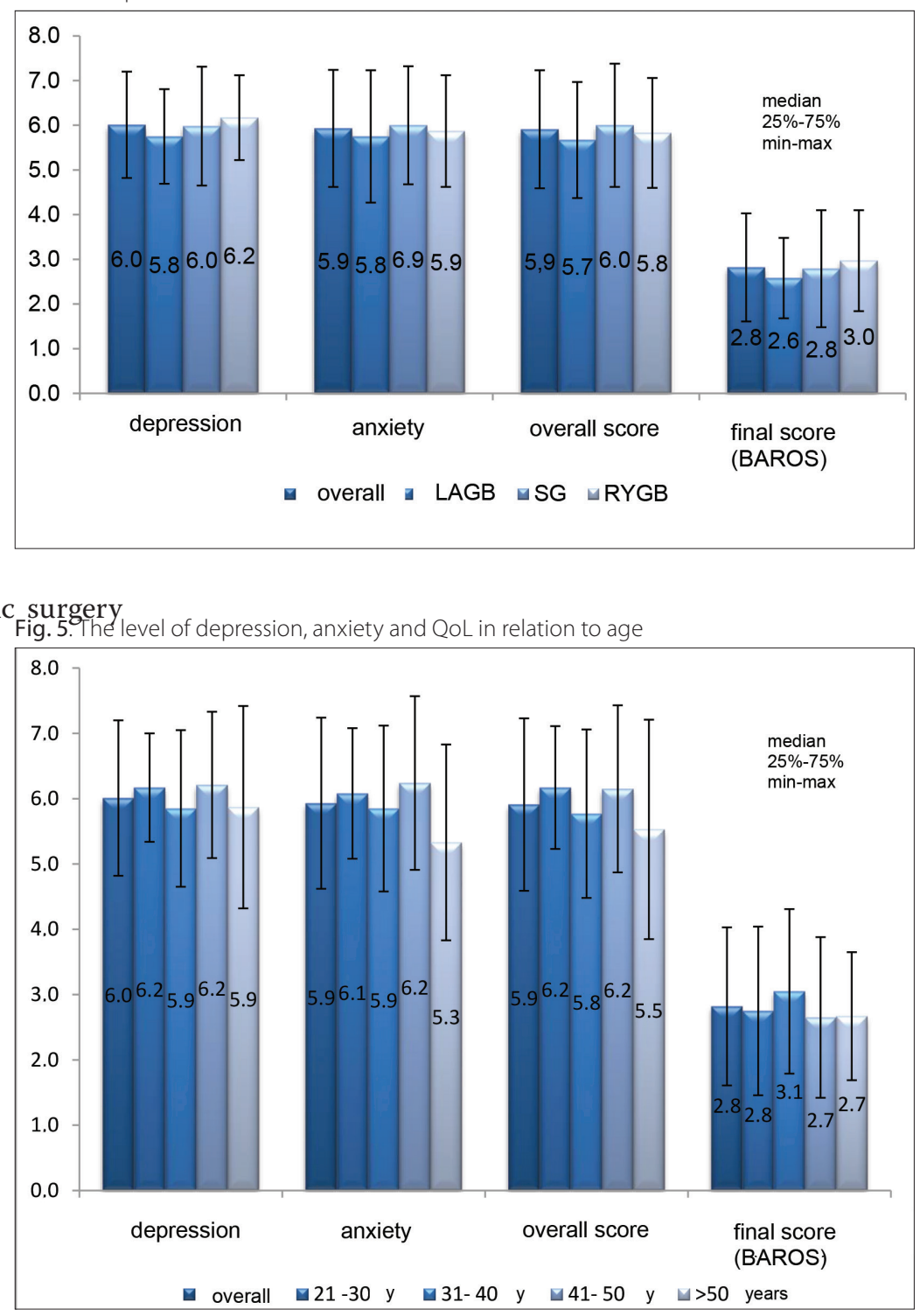

Fig. 6. The level of depression, anxiety and QoL in relation to sex

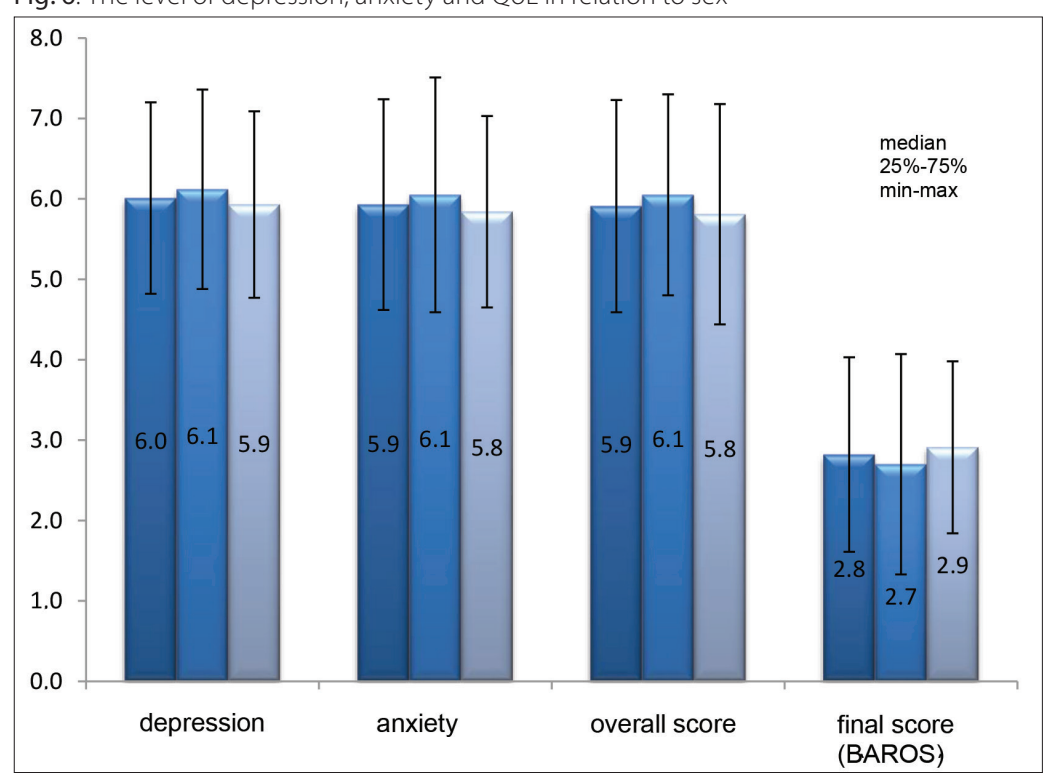




\section{Study limitations}

The study should be repeated $2-5$ years after bariatric surgery to assess QoL and depression levels.

In conclusion, our results are consistent with those studies that found improvement but not in all aspects of HRQoL. The time since surgery had the greatest impact on QoL after bariatric surgery, regardless of type. We have come to the conclusion that MA-QoL II is a useful tool in assessing bariatric surgery, including QoL. Longterm monitoring will be essential in determining psychological changes and the degree of weight loss.

The individually selected bariatric surgery procedure determines the effectiveness of treatment by average weight loss and long-term maintenance. This includes improving health, control of comorbidities, reduction of psychological problems, and high QoL. Currently, the laparoscopic method dominates, and multidisciplinary teams are more and more appreciated in perioperative care, guaranteeing the safety and effectiveness.

\section{References}

1. Ono T, Guthold R, Strong K. WHO Global Comparable Estimates, 2005. Available at: http://www.int/infobasellBR. Accessed on: March 15, 2009.

2. Buchwald $\mathrm{H}$, Avidor $\mathrm{Y}, \mathrm{Braunwald} \mathrm{E}$. Bariatric surgery. A systematic review and meta-analisis. JAMA. 2004; 292(14):1724-1737.

3. Zdrojewski T, Bandosz P, Szpakowski $P$, et al. Rozpowszechnienie głównych czynników ryzyka chorób układu sercowo-naczyniowego w Polsce. Wyniki badania NATPOL PLUS. Kardiol Pol. 2004;61(suppl IV);1IV-26.

4. Szponar L, Sekuła W, Nelson M, Weisell RC. The household food consumption and anthropometric survey in Poland. Public Health Nutr. 2001;4(5B):1183-1186.

5. Biela U,PająkA, Kaczmarczyk-ChałasK, etal.Częstość występowania nadwagi i otyłości u kobiet i mężczyzn w wieku 20-74 lat. Wyniki programu WOBASZ. Kardiol Pol. 2004;63(Suppl IV):S632-635.

6. Babińska Z, Trzeciak BG, Bandosz P, et al. Prevalence of overweight and obesity in village population -,,Kełpino Trial”. Fam Med Prim Care Rev. 2006;8:569-571.

7. World Health Organization. Obesity. Preventing and Managing the Global Epidemic. WHO Technical Report Series No.894. Geneva: WHO 2000.

8. Dubiński A, Zdrojewicz Z. The influence of obesity, distribution of fat tissue and leptin on risk of developing of cardiovascular disease in women. Adv Clin Exp Med. 2006;15(6):1047-1053.

9. Sarwer DB, Wadden TA, Fabricatore AN. Psychological and behavioral aspects of bariatric surgery. Obes Res. 2005;13(4):639-648.
10. Mariano ML, Monteiro CS, de Paula MA. Bariatric surgery: Its effects for obese in the workplace. Rev Gaucha Enferm. 2013;34(3):38-45.

11. Hady HR, Zbucki R $九$, Łuba ME, et al. Obesity as a social disease and the inflence of environmental factors on BMI in own material. Adv Clin Exp Med. 2010;19(3):369-78.

12. Roberts RE, Deleger S, Strawbridge WJ, et al. Prospective association between obesity and depression: Evidence from the Alameda County Study. Int J Obes Relat Metab Disord. 2003;27(4):514-521.

13. DeMaria EJ. Bariatric surgery for morbid obesity. $N$ Engl J Med. 2007;356:2176-2183.

14. Adams KF, Schatzkin A, Harris TB, et al. Overweight, obesity, and mortality in large prospective cohort of persons 50 to 71 years old. N Engl J Med. 2006,24; 355(8):763-778.

15. Wyleżoł M, Paśnik K, Dąbrowiecki S, et al. Polish recommendations for bariatric surgery. Videosurgery Miniinv. 2009,4(suppl 1),31-34.

16. Maggard MA, Shugarman LR, Suttorp M, et al. Meta-analysis: Surgical treatment of obesity. Ann Intern Med. 2005,5;142(7):547-559.

17. Brolin RE. Bariatric surgery and long-term control of morbid obesity. JAMA. 2002;288(22):2793-2796.

18. Kolotkin RL, Head S, Hamilton M, Tse CK. Assessing impact of weight on quality of life. Obes Res. 1995;3;49-56.

19. Fabricatore AN, Wadden TA, Sarwer DB, et al. Health-related quality of life and symptoms of depression in extremely obese persons seeking bariatric surgery. Obes Surg. 2005;15:304-309.

20. Oria HE, Moorehead MK. Bariatric Analysis and Reporting Outcome System (BAROS). Obes Surg. 1998;4:87-99.

21. Nini E, Slim K, Scesa JL, et al. Evaluation de la chirurgie coelioscopique de l'obesite par le score BAROS. Ann Chir. 2002;127(2):107-114.

22. Kokoszka A. Brief Self-Rating Scale of Depression and Anxiety: Description of the scale's construction and psychometric properties for persons with diabetes. Przewodnik Lekarza. 2008;6:74-81.

23. Bobowicz M, Lehmann A, Orłowski M, et al. Preliminary outcomes 1 year after laparoscopic sleeve gastrectomy based on Bariatric Analysis and Reporting Outcome System (BAROS). Obes Surg. 2011;21(12):1843-1848.

24. Ribaric G, Buchwald JN, d'Orsay, et al. 3-year-world outcomes with the Swedish gastric band, ${ }^{\text {tm }}$ in France. Obes Surg. 2013;23(2):184-196.

25. Zuegel NP, Lang RA, Hüttl TP, et al. Complications and outcome after laparoscopic bariatric surgery: LAGB versus RYGB. Langenbecks Arch Surg. 2012;397:1235-1241.

26. Dadan J, Iwacewicz P, Razak Hady H. Quality of life evaluation after selected bariatric procedures using the Bariatric Analysis and Reporting Outcome System. Videosurgery Miniinv 2010;5(3):93-99.

27. Sierżantowicz R, Razak Hady H, Kirpsza B, et al. Quality of life of patients after bariatric treatment-preliminary report. Prog Health Sci. 2012;2(1):89-94.

28. Hady HR, Dadan J, Łuba M. The influence of laparoscopic sleeve gastrectomy on metabolic syndrome parameters in obese patients in own material. Obes Surg. 2012;22(1):13-22.

29. Hady HR, Dadan J, Gołaszewski P. 100 obese patients after laparoscopic adjustable gastric bading the influence on BMI, Gherlin and insulin concentration, parameters of lipid balance and comorbidities. Adv Med Sci. 2012;57(1):58-64.

30. Burgmer R, Petersen I, Burgmer M, et al. Psychological outcome two years after restrictive bariatric surgery. Obes Surg. 2007;17:785-791. 